\title{
Characteristic of person-centered care as documented in medical records at a medical department - A mixed methods
}

\author{
Kristina Rosengren*1,2, Kerstin Ulin ${ }^{1,2}$, Eric Carlström ${ }^{1,2}$ \\ ${ }^{1}$ Sahlgrenska Academy, Institute of Health and Care Sciences, University of Gothenburg, Sweden \\ ${ }^{2}$ University of Gothenburg Centre for Person-Centred Care (GPCC), Gothenburg, Sweden
}

Received: June 25, 2018

DOI: $10.5430 /$ jha.v8n2p7
Accepted: August 19, 2018

Online Published: February 25, 2019

\begin{abstract}
Objective: Few studies describe characteristics of content of person-centrered care (PCC) in hospital care. Therefore, this study aim to describe and compare documentation in medical records regarding content of PCC for two diagnostic groups; Chronic Obstructive Pulmonary Disease (COPD) and Chronic Heart Failure (CHF) at a medical department in a hospital in Sweden.

Methods: Documentation within medical records $(\mathrm{n}=121)$ regarding content of PCC (patient resources, responsibility, i.e. partnership) were analysed by a mixed methods.

Results: The results describe documented health care activities (medical records) among patients $\left(\mathrm{COPD}^{1}=88 ; \mathrm{CHF}^{2}=33\right.$ ) treated at medical wards practicing PCC $\left(n=69,39^{1} / 30^{2}\right)$ and traditional medical wards $\left(n=52,49^{1} / 3^{2}\right)$. The study showed limited documentation in all medical records regardless of care; however, patients with CHF have higher documentation regarding content of PCC compare to COPD in 6 (symptoms, home situation, objectives, caring activities, patients resources, continuing care) out of 7 areas (planning processes).

Conclusions: To improve health care with limited resources, there is need to switch mind-sets from what (diagnosis) to who (resources) using all evidence (expert $=$ scientific to expert $=$ lived experiences) by collecting narratives to facilitate mutual health plans (partnership). This change in healthcare organisation facilitates by transformative and shared leadership to improve teamwork (health professionals, patient, relative) in partnership with all involved.
\end{abstract}

Key Words: Managerial aspects, Medical records, Mixed methods, Partnership, Person-centred care, Teamwork

\section{INTRODUCTION}

Almost all health care in Sweden is founded by taxes and the allocation of common resources puts focus on the efficiency of governmental needs and goals. The increasing number of elderly does gradually consume a more and more extensive part of the health care forcing stakeholders to prioritize limited public resources between generations. ${ }^{[1]}$ Another perspective is that new technology creates more options re- garding diagnosing and treatments but raise the costs and contribute to a competition of available resources. ${ }^{[2-4]}$ During an upcoming generation and technology driven competition of public resources, the ability of the patient seems to be forgotten. As a contrast to an impersonal public healthcare a movement, person-centred care (PCC) has rapidly become popular. PCC is an approach grounded in philosophy about being a person (patient, relatives, staff) and the

\footnotetext{
* Correspondence: Kristina Rosengren, Assoc. Prof.; Email: kristina.rosengren@ gu.se; Address: Sahlgrenska Academy, Institute of Health and Care Sciences, University of Gothenburg, Sweden.
} 
kind of resources the person possess. Patients' narrative, the partnership and documentation in a co-creation is a teamwork between the patient and the health care professionals. This cornerstones is the key factors in PCC to focus on available resources possessed by the patient rather than routines and technology in the health care sector. ${ }^{[5-8]}$

\section{Background}

Implementation of person-centeredness in Swedish healthcare is considered to be hindered by organizational boundaries that becomes obvious when patients move between hospitals, primary health, community health and/or social care. A strict separation of budgets between caregivers maintains procedures that disadvantage continuity and collaboration. This problem becomes apparent when admissions and discharges from hospital lack adequate care planning. It is well known that patients who receive primary care and home healthcare are sent to hospital without sufficient consideration. ${ }^{[9-11]}$ One of the effects is overcrowded emergency departments and long waiting time for discharge from inpatient care, especially for multiple comorbidity and frail elderly persons. ${ }^{[12]}$ In addition, when patients are transitioned between in-patient care, municipal home care service and/or roundthe-clock home nursing, nursing homes and primary care centres, health plans are still missing. It is known that lack of planning contributes to frequent use of healthcare. ${ }^{[2-4,13,14]}$ Elements of paternalism, path-dependent behaviour and organizational inertia has been identified as reasons to the lack of health care professionals-patient partnership. ${ }^{[15,16]}$ However, a successful implementation of person-centeredness has proven to improve the health care professionals-patient partnership. Such a partnership starts with patient's narrative, recorded and documented in a structured manner. The narrative in combination with traditional examinations and test results make a common ground for a mutual health care plan. It incorporates goals and strategies such as discharge planning as well as short and long term follow-up. ${ }^{[5-8]}$ The impact of PCC has been questioned regarding routines and procedures in the clinic. ${ }^{[17]}$ Consequently, the aim was to study the impact of PCC by describing and comparing medical records from two diagnostic groups, chronic obstructive pulmonary disease (COPD) and chronic heart failure (CHF) at a medical department in a hospital in Sweden.

\section{METHOD}

\subsection{Settings}

The lack of knowledge regarding the presence of practicing PCC during hospital stays and transfers between caregivers motivated the use of a mixed method. ${ }^{[18]}$ The study was conducted in a medical department at a university hospital with 1,200 beds and 17,000 staff members in the western county of Sweden populated with 1.6 million inhabitants. PCC was implemented in five different hospital wards from the year 2010 to 2013. Using PCC assumes that the experiences, individual conditions, resources and restraints of the patient are considered and documented in order to improve the outcome of the health care. The movement from standardized to person-centred is expected to be documented in a mutual care plan within $24-72$ hours from arrival to the caregiver. ${ }^{[17]}$

\subsection{Sample and data collection}

Inclusion criteria were medical records regarding the two diagnostic groups (COPD and $\mathrm{CHF}$ ) was divided into four wards (50\% practicing PCC, 50\% non-practicing PCC) at a medical department, university hospital in western part of Sweden. The medical records were selected and followed from January 2015 to December 2015 (121 medical records were included, see Table 1) and were divided into two parts, patients with hospital stay in a medical wards practicing PCC $(\mathrm{COPD}=39, \mathrm{CHF}=30)$ and wards with no PCC $(\mathrm{COPD}=$ $49, \mathrm{CHF}=3$ ). Exclusion criteria were patients in hospice care.

Table 1. Overview of data

\begin{tabular}{llll}
\hline & PCC/Non PCC ward & Diagnosis & Diagnosis/Care approach \\
\hline & PCC ward & COPD & PCC COPD \\
& $\mathrm{n}=69$ & $\mathrm{n}=88$ & $\mathrm{n}=39$ \\
& Non PCC ward & & Non PCC COPD \\
Number of & $\mathrm{n}=52$ & $\mathrm{CHF}$ & $\mathrm{n}=49$ \\
patients & & $\mathrm{n}=33$ & $\mathrm{PCC}$ CHF \\
& & & $\mathrm{n}=30$ \\
& & & Non PCC CHF \\
& & $\mathrm{N}=121$ & $\mathrm{n}=3$ \\
\hline Total & $\mathrm{N}=121$ & $\mathrm{~N}=121$ \\
\hline
\end{tabular}




\subsection{Data analysis}

We used mixed methods, ${ }^{[18]}$ descriptive statistics and qualitative content analysis ${ }^{[20]}$ to map how PCC is documented in medical records for two diagnostic groups (COPD and $\mathrm{CHF}$ ) at medical wards. The method was used to identify conflicting opinions and unsolved issues regarding meaning and use of concepts, procedures and interpretation. The concepts of PCC were based on well-documented personcentred approach, ${ }^{[5-8]}$ i.e. patient as an equal partner and obligation of staff to promote interaction regarding health plans together with different caregivers (inpatient and home healthcare). The review of medical records included diagnosis, symptoms/functions, home situation, goals to fulfil, care planning, caring activities, patient's resources and continuing care (next caregiver). The quantitative approach involved measurement and quantification of numbers. Descriptive statistics (Microsoft Excel, 2013) were used for analysis of the reviews of medical records variables (see Table 1). Data was presented in proportion (\%) focusing content of PCC care, and findings are presented in Tables 2-4.

\subsection{Ethical considerations}

Ethical approval and permission for the study was obtained from the regional ethical review board (diary number 098-15) and the manager of the medical department. No information about individual patients was obtained though respect for the individuals was a main concern during the study why confidentially were kept. In addition, a scientific systematic data analysis was performed to ensure validity and reliability of results. Ethical guidelines for human and social research were considered throughout the study. ${ }^{[21]}$

\section{Results}

The results are divided in two parts, descriptive proportion regarding documented healthcare activities (medical records) in relation to content of PCC due to if patients diagnosed with COPD and CHF treated at medical wards that practicing PCC $(n=69)$ or non-practicing PCC medical wards $(n=52)$. The other part, focus on how PCC is described in medical records.

\subsection{Documented healthcare activities in relation to $\mathrm{PCC}$ due to patients diagnosed with COPD and CHF}

Over all, the results showed a modest documentation in line with PCC regardless of care (PCC, non PCC) and content (symptoms/functions, home situation, goals to fulfil, care planning, caring activities, patients resources, continuing care). However, wards practicing PCC $(n=69)$ documented more in line with the content of PCC (patient resources, responsibility, i.e. partnership) regarding symptoms/functions, home situation, goal to fulfil, patient's individual resources (effort and responsibility) and continuing care (next caregiver) then non-PCC wards $(n=52)$, see Table 2.

Table 2. Documented PCC activities in medical records

\begin{tabular}{lll}
\hline Documentation according to PCC & PCC ward (\%) & Non PCC ward (\%) \\
\hline Symptom/function & 36 & 15 \\
Home situation & 29 & 12 \\
Goal settings & 29 & 12 \\
Care planning & 22 & 37 \\
Caring activities & 39 & 42 \\
Patients resources & 29 & 77 \\
Continuing care & 22 & 73 \\
\hline
\end{tabular}

Accordingly, the results showed differences regarding the visibility of PCC in the medical records, for example documentation of symptoms/functions from a patient's perspective were more visible in medical records when staff used PCC approach (PCC 36\%) than traditional care (non PCC $15 \%)$. However, medical records in non-PCC wards showed more elaborated records regarding care planning and caring activities compared to medical records from PCC-wards (see Table 3). Moreover, patient suffering from CHF treated at medical PCC-wards (30 out of 33) showed more substantial documentation regarding content of PCC (patient resources, responsibility, i.e. partnership) than patients suffering from COPD (39 out of 88). The use of patient's resources when planning the health care differed between the two diagnostic groups $(\mathrm{CHF}=97.7 \%$; $\mathrm{COPD}=74.4 \%)$. In addition, the study showed differences regarding symptoms/functions (CHF 53.3\%; COPD 20.5\%), home situation (CHF 44.3\%; COPD 15.4\%), caring activities (CHF 63.3\%; COPD 20.5\%), and continuing care (CHF 90\%; COPD 76.9\%) as shown in Table 3. 
Table 3. Documented PCC activities, comparison COPD-CHF

\begin{tabular}{lll}
\hline Documentation according to PCC & COPD $(\mathbf{n}=\mathbf{3 9})$ & $\mathbf{C H F}(\mathbf{n}=\mathbf{3 0})$ \\
\hline Symptom/function & $20.5 \%$ & $53.3 \%$ \\
Home situation & $15.4 \%$ & $43.3 \%$ \\
Goal settings & $17.9 \%$ & $23.3 \%$ \\
Care planning & $20.5 \%$ & $16.7 \%$ \\
Caring activities & $20.5 \%$ & $63.3 \%$ \\
Patients resources & $74.4 \%$ & $97.7 \%$ \\
Continuing care & $76.9 \%$ & $90 \%$ \\
\hline
\end{tabular}

The results showed differences in relation to age. The patients who suffered from CHF were older then patients with COPD (80.2 year COPD and 88.4 year CHF). However, the study showed significant differences ( 5 out of 8 factors) regarding comparison of means (STD) of documented PCC due to diagnosis (COPD-CHF), especially regarding home situation (1.8 COPD, 2.8 CHF). Despite of age, the patients who suffered from CHF $(n=30)$ were more involved in building the care plan than patients with COPD $(n=39)$, see Table 4.

Table 4. Comparison of means (STD) of documented PCC due to diagnosis

\begin{tabular}{lll}
\hline Documentation according to PCC & Means PCC COPD $(\mathbf{n}=\mathbf{3 9})$ & Means PCC CHF $(\mathbf{n}=30)$ \\
\hline \multirow{2}{*}{ Symptom/function } & $1.9(1.2)$ & $3.0(1.3)$ \\
Home situation & $p<.05$ & $p<.05$ \\
Goal settings & $1.8(1.3)$ & $2.8(1.1)$ \\
Care planning & $p<.01$ & $p<.01$ \\
Caring activities & $1.7(1.3)$ & $1.9(1.3)$ \\
Patients resources & $1.8(1.5)$ & $1.7(1.3)$ \\
Continuing care & $2.02(1.2)$ & $3.07(1.1)$ \\
Hospital stay & $p<.01$ & $p<.01$ \\
Age & $3.3(1.4)$ & $4.1(0.6)$ \\
& $3.4(1.2)$ & $4.1(0.5)$ \\
& $p<.05$ & $p<.05$ \\
& $5.6(5.7)$ & $7.2(4.3)$ \\
& $80.2(9.3)$ & $88.4(4.2)$ \\
\hline
\end{tabular}

\subsection{Content of documented healthcare in relation to person-centred approach}

The second part of the results described the documentation of PCC in medical records $(n=69)$ at the PCC-wards due to use of words focusing on partnership (patient, relatives, staff). The PCC-wards used more general Swedish words and less Latin or medical jargon, for example "infections in his/her lungs" instead of "pneumonia". A person-centred approach could be viewed in the text of medical records such as:

“... dialogue with patients and review of basic diseases, no use at present to carry out further investigations or new medications, got support from physiotherapist regarding mobilization and advice on home exercise. Patient is satisfied with the decision and agree regarding the care plan." (Women 73 year)

“... carried out investigations, initiate treatment of heart failure with fluid-inducing medication to facilitate breathing, body examination, sampling, patient receiving a mutual care plan describing the cause of admission, examinations, assessments and treatment. Offered care planning, patient decide to say no to further care planning though patient highlight that it works well at home without adding more home care." (Man 95 year)

Another example to describe PCC in medical records was the use of narrative with focus on patient's resources as a tool in the rehabilitation phase.

“... would like to dance again and to visit a dance competition that are running in a few weeks, very active, good social 
life situation.” (Women 75 year)

“... The patient thinks she got enough home health care right now, the patient believes that she can manage a cord at home despite impaired eyesight." (Woman 82 year)

The practice of PCC was visible by a scheduled hospital stay already included in the first mutual care plan:

“... Scheduling with cardiac monitoring, blood samples, ultrawaves and $X$-ray chest and heart. Planning treatment with diuretic and antihypertensive medications, expected hospital stay 4-7 days. Care plan is written, the nurse go through the content as planning, investigation, treatment and continued care. The patient get successfully recovery when he is admitted from hospital; follow up at the clinic for heart failure." (Man 87 year)

Moreover, documentation regarding patient's resources was frequently described in medical records from PCC-wards compare to non-PCC wards.

“... Have driving license and drive his car... Self-managing daily living activities, is verbal and communicative." (Man 82 year)

"... Like to take a walk, visit theatre and be with her children and friends." (Women 79 year)

Furthermore, the content in the mutual care plan was documented as discussions between staff members such as nurses/physicians and patients as well as relatives, which is exemplified in the following text:

“... the patient is very determined and don't wanted to be actively exercised, training independently with PEP, does not want home healthcare, say no to care planning." (Man 74 year)

“... Have been happy to try $x x$ for help quit smoking. The patient does not feel able to go home today despite being relatively affected and therefore she stay for another few days." (Woman 80 year)

“... The patient is informed of cause of hospital stay, results of blood samples and treatment. Meet a physiotherapist because that patient feels unstable when he walks ... Nurse informs his wife of the planned admission home. Say no to care planning, denies meeting with staff from community care. It works well with the wife's home service." (Man 69 year)

"... Say no to care planning, gradually improved, the patient will arrange follow-up at the health centre by herself." (Women 58 year)

In summary, documentation regarding content of PCC in medical records was modest regardless of care (PCC, non PCC) and content (symptoms/functions, home situation, goals to fulfil, care planning, caring activities, patients resources, continuing care). The majority of all text in medical records focused on physiological health care aspects.

\section{Discussion}

This study's aim was to compare documentation regarding content of PCC in medical records for two diagnostic groups (COPD, CHF) at a medical department in a hospital in Sweden. The medical and care planning records were analysed regarding diagnosis, symptoms/functions, home situation, goals to fulfil, care planning, caring activities, patient's resources and continuing care (next caregiver). The results showed differences due to diagnosis PCC-wards. Patients with CHF $(n=30)$ showed more documented care activities in line with PCC than medical records from patients suffering from COPD $(n=39)$. Another aspect was that 30 out of $33 \mathrm{CHF}$ patients stayed at a PCC-ward, compared to 39 out of 88 COPD patients. Those differences could be related to wards working according to PCC approach, documented more frequently than non PCC-wards, i.e. an effective hospital care with less hospital stays. ${ }^{[22-24]}$ In addition, the results show a modest number of medical records in line with PCC regardless of wards (PCC/non PCC) or diagnosis (CHF, COPD) why improvement is needed to visualize all resources (patients, health professionals) to improve health care and quality of life. ${ }^{[7,8,25]}$ One example is prolonged hospital stay, re-admission and less satisfied patients due to lack of partnership that influence recovery and/or rehabilitation as well as quality of life. Improving healthcare due to limited resources, partnership and teamwork (patient, relatives, staff) is key factors to acknowledge patients experiences of his/her body and everyday life situation, as well as health professional's knowledge in caring and curing. Research shows ${ }^{[22-27]}$ that PCC is one tool to fulfil this gap, though health care need to improve the use of available resources (staff/patients experiences, knowledge).$^{[7,10]}$ It could be viewed as unethical only to use part of the resources that are evidence based (health professionals knowledge) though patients experiences is significant to improve quality of care. ${ }^{[1,28]}$

One conclusion of the results is that health professionals think they work according to PCC, but the concrete working organisation is still not structured to a PCC approach. ${ }^{[7]}$ By highlight resources instead of shortcomings such as health problems, tacit knowledge can be visible and documented. ${ }^{[7]}$ Such partnership has proven to be dependent on agreements between patients and health professionals. ${ }^{[8]}$ PCC approach ${ }^{[19]}$ is highlighted as a switch of mind-sets by health professionals and patients, from what a patient are, di- 
agnosis as CHF, COPD with health problems, moving to who the patient is (strengths, resources, interests = forces) that could be used to improve health by using available resources. In Sweden there is a growing movement in implementing PCC,${ }^{[19]}$ that include a structural working organisation (narrative, mutual health plan) in partnership, i.e. shifting mind-set in a structural teamwork. ${ }^{[10,25]}$ All health professionals (assistant nurses, nurses, occupational therapists, physicians, physiotherapists etc.) and patient's as well as relatives follow a mutual health plan as partners (expert-expert). This organisational change is considered to need a firm leadership ${ }^{[28]}$ to improve a public health care with long traditions and deeply rooted routines. For example, research showed that implementation of PCC in a hierarchical health care organisation need a structural working approach built on evidence-based knowledge, no ad hoc way of working. ${ }^{[8,10,25]}$ Moreover, a relationship based leadership as transformative leadership ${ }^{\text {[29] }}$ and shared leadership ${ }^{[30]}$ is one way of change mind-sets in health care. Leader's/manager's role is to find solutions to improve quality of care by using all available resources in health care working together all actors involved as a team (health professions, patients, relatives), all on board with no exception. ${ }^{[19]}$

\section{Limitations}

A limitation of this study is that data is collected from one medical department at one university hospital in Sweden. However, the data collection was performed within four different medical wards (2 traditional care, 2 PCC-approach), which makes the study results more transferable. However, the degree of transferability of these results to other settings outside medical departments must be considered carefully, why more studies are needed in other settings with other diagnostic groups then COPD and CHF. Furthermore, the trustworthiness of the results ${ }^{[18,20,21]}$ was ensured through a scientific systematic analysis that used well-documented methodology of mixed methods. ${ }^{[18]}$ Our data from medical records improve our knowledge regarding content of PCC in relation to hospital stays, which could improve PCC during hospital care. However, the study's validity should be discussed considering to its limitations above, why further studies are needed to develop knowledge of the characteristics of PCC.

\section{Conclusions}

Limited documentation in line with PCC approach highlighted a switch of mind-sets by health professionals and patients, from what a patient are (object) to who the patient is (resources) to improve health care, i.e. using all available resources (expert-expert, synergy effects) though it is unethical to miss use limited resources in health care. Manage and lead a structural teamwork (health professionals, patient, relatives) that include collecting narrative to build a mutual health plan in partnership (expert to expert) with all involved need a kind but firm leadership to improve health care with limited resources. A relation based leadership as transformative leadership as well as shared leadership based on PCC approach is leadership models that facilitate change of mind-sets in healthcare organisations (resources versus problem/needs) to use limited resources based on evidence (scientific, lived experiences).

\section{ACKNOWLEDGEMENTS}

The authors would like to acknowledge the University of Gothenburg Centre for Person-Centred Care (GPCC), Sahlgrenska Academy, University of Gothenburg, Gothenburg, Sweden.

\section{FUNDING}

The authors received financial support for the research from the University of Gothenburg Centre for Person-Centred Care (GPCC), Sahlgrenska Academy, Sweden.

\section{CONFLicts OF INTEREST Disclosure}

The authors declared no potential conflicts of interest with respect to the research, authorship, and/or publication of this article.

\section{REFERENCES}

[1] Swedish Code of Statutes. SFS 1982:763/SFS 2014:822/SFS 2017:30. Hälso- och sjukvårdslagen (Health and Medical Services Act). (accessed 16 October 2017). Available from: www.riksdagen. se/sv/dokument-lagar/dokument/svensk-forfattningss amling/halso--och-sjukvardslag-201730_sfs-2017-30

[2] Alexander JA, Hearld LR. The science of quality improvement implementation developing capacity to make a difference. Med Care. 2011; 49(suppl): S6-20. PMid: 20829724. https ://doi .org/10 .1097/MLR. 0b013e3181e1709c
[3] Baker RG. The contribution of case study research to knowledge of how to improve quality of care. BMJ Qual Saf. 2011; 20(suppl): i30i35. PMid: 21450767. https://doi.org/10.1136/bmjqs. 2010 .046490

[4] Grol R, Grimshaw J. From best evidence to best practice: effective implementation of change in patients' care. Lancet. 2003; 36(9391): 1225-1230. https://doi.org/10.1016/S0140-673 $6(03) 14546-1$

[5] McCormack B, McCance TV. Development of a framwork for person- 
centred nursing. J Adv Nurs. 2006; 56(5): 472-479. PMid: 17078823. https://doi.org/10.1111/j.1365-2648.2006.04042.x

[6] Morgan S, Yoder L. A Concept Analysis of Person-Centered Care. J Holist Nurs. 2012; 30(1): 6-15. PMid: 21772048. https ://doi .or $\mathrm{g} / 10.1177 / 0898010111412189$

[7] Ekman I, Swedberg K, Taft C, et al. Person-centered care - Ready for prime time. Eur J Cardiovasc Nurs. 2011; 10(4): 248-251. PMid: 21764386. https://doi.org/10.1016/j.ejcnurse.2011.06 .008

[8] Alharbi T, Ekman I, Olsson LE, et al. Organizational culture and the implementation of person-centred care: Results from a change process in Swedish hospital care. Health Policy. 2012; 108(2-3): 294-301. PMid: 23069131. https://doi.org/10.1016/j.heal thpol.2012.09.003

[9] Wadmann S, Strandberg-Larsen M, Vrangbæk K. Coordination between primary and secondary healthcare in Denmark and Sweden. Int J Integr Care. 2009; 9(1): e04. PMid: 19340328. https : //doi.org/10.5334/ijic. 302

[10] Carlström E. Strategies for Change - Adaption to new accounting conditions. J Account Organ Change. 2012; 8(1): 41-61. https: //doi.org/10.1108/18325911211205739

[11] Gandhi TJ, Lee TH. Patient Safety Beyond Hospital. N Engl J Med. 2010; 363(11): 1001-1003. PMid: 20825311. https://doi.org/ 10.1056/NEJMp1003294

[12] Bauer M, Fitzgerald L, Haesler E, et al. Hospital discharge planning for frail older people and their family. Are we delivering best practice? A review of the evidence. J Clin Nurs. 2009; 18(18): 25392546. PMid: 19374695 . https://doi.org/10.1111/j.1365-2 $702.2008 .02685 . \mathrm{x}$

[13] Olofsson P, Carlström E, Bäck-Pettersson S. During and beyond the triage encounter: Chronically ill elderly patient's experiences throughout their emergency department attendances. Int Emerg Nurs. 2012; 20(4): 207-213. PMid: 23084509. https://doi.org/10.1 016/j.ienj.2012.03.006

[14] Mathers N, Thomas M. Integration of care: a bridge too far? $\mathrm{Br}$ J Gen Pract. 2012; 62(601): 402-403. PMid: 22867654. https: //doi.org/10.3399/bjgp12X653462

[15] Alvebratt C, Carlström C, Åström S, et al. The process of implementing a new working method - a project towards change in a Swedish psychiatric clinic. J Hosp Adm. 2014; 3(6): 174-189. https://doi.org/10.5430/jha.v3n6p174

[16] Carlström E, Olsson LE. The association between subcultures and resistance to change - in a Swedish hospital clinic. J Health Organ Manag. 2014; 28(4): 458-476. PMid: 25241594. https: //doi.org/10.1108/JHOM-09-2012-0184

[17] Wolf A, Ulin K, Carlström E. Changing the ward culture in a clinic during the implementation of person-centred care. J Hosp Adm. 2017; 6(5): 31-39. https://doi.org/10.5430/jha.v6n5p31
[18] Tashakkori A, Teddlie C. (eds) Handbook of Mixed Methods in Social \& Behavioral Research. Thousands Oaks: SAGE; 2003.

[19] Rosengren K. Person-centred care: A qualitative study on first line managers' experiences on its implementation. Health Serv Manag Res. 2016; 29(3): 42-49. https ://doi .org/10.1177/09514848 16637748

[20] Graneheim UH, Lundman B. Qualitative content analysis in nursing research: concepts, procedures and measures to achieve trustworthiness. Nurse Educ Today. 2004; 24(2): 105-112. PMid: 14769454 https://doi.org/10.1016/j.nedt.2003.10.001

[21] Codex. Rules \& guidelines for research. The humanities and social sciences. 2017. Available from: www. codex.vr.se/en/forskni nghumsam.shtm 1

[22] Dudas K, Olsson LE, Wolf A, et al. Uncertainty in illness among patients with chronic heart failure is less in person-centred care than in usual care. Eur J Cardiovasc Nurs. 2013; 12(6): 521-528. PMid: 23303766. https://doi.org/10.1177/1474515112472270

[23] Fors A, Ekman I, Taft C, et al. Person-centred care after acute coronary syndrome, from hospital to primary care - a randomised controlled trial. Int J Cardiology. 2015; 187: 693-699. PMid: 25919754 https://doi.org/10.1016/j.ijcard.2015.03.336

[24] Ekman I, Wolf A, Olsson LE, et al. Effects of person-centred care in patients with chronic heart failure: the PCC-HF study. Eur Heart J. 2012; 33(9): 1112-1119. PMid: 21926072. https ://doi.org/10 .1093/eurheartj/ehr306

[25] Moore L, Britten N, Lydahl D, et al. Barriers and facilitators to the implementation of person-centred care in different healthcare contexts. Scand J Caring Sci. 2016; 31(4): 662-673. PMid: 27859459. https://doi.org/10.1111/scs.12376

[26] Hansson E, Ekman I, Swedberg K, et al. Person-centred care for patients with chronic heart failure-a cost-utility analysis. Eur $\mathbf{J}$ Cardiovasc Nurs. 2015; 15(4): 276-284. PMid: 25595358. https : //doi.org/10.1177/1474515114567035

[27] Ulin K, Olsson LE, Wolf A, et al. Person-centred care-An approach that improves the discharge process. Eur J Cardiovasc Nurs. 2016; 15(3): e19-e26. PMid: 25648848. https://doi.org/10.1177/ 1474515115569945

[28] Rosengren K, Höglund P, Hedberg B. Quality register: a tool for patient advantages - from a caring perspective. J Nurs Manag. 2012; 20(2): 196-205. PMid: 22380414. https://doi.org/10.1111/j. 1365-2834.2012.01378. $x$

[29] Bass BM, Avolio BJ, Jung DI, et al. Predicting Unit Performance by Assessing Transformational and Transactional Leadership. J Appl Psychol. 2003; 88(2): 207-218. PMid: 12731705. https: //doi.org/10.1037/0021-9010.88.2.207

[30] Rosengren K, Bondas T. Supporting "two-getherness": Assumption for nurse managers working in a shared leadership model. Intensive Crit Care Nurs. 2010; 26(5): 288-295. PMid: 20837321. https://doi.org/10.1016/j.iccn.2010.08.002 